\title{
Electronically Tunable Inductance Simulator for Monitoring Biomedical Signals
}

\author{
A. Chaichana and W. Jaikla
}

\begin{abstract}
This article presents grounded inductance simulator using single current controlled current differencing transconductance amplifier (CCCDTA) as active element. The simulated inductance value can be controlled electronically by adjusting the bias current of the CCCDTA. The grounded inductance simulator comprises one CCCDTA and one grounded capacitor without any external resistors and component matching requirements. The circuit performances are depicted through PSpice simulations, they show good agreement to theoretical anticipation. An application as second-order low-pass filter is included to confirm the usability of proposed circuit. It is very suitable to realize the proposed filter in monolithic chip to use in biomedical signal processing.
\end{abstract}

Index Terms-CCCDTA, inductance simulator, integrated circuit.

\section{INTRODUCTION}

Recently, the desirability of building active filters and biomedical signal processing circuits without the use of physical coils has been interested. Although, a spiral inductor can be realized in an integrated circuit, it still has some drawbacks in the usage of space, weight, cost and tunability. The inductance simulators can be used in many applications such as active filter design, oscillator design, analog phase shifters and cancellation of parasitic element [1]. In biomedical application, the inductance simulator is the importance part in power feed circuit [2].

The attention is subsequently focused on the inductance simulator using different high-performance active building blocks such as, operational transconductance amplifiers (OTAs), current feedback op-amps, and four-terminal floating nullors (FTFNs), current conveyors, current differencing buffered amplifier (CDBAs), etc. The literature surveys show that a large number of circuit realizations for inductance simulators have been reported [3]-[17]. Unfortunately, these reported circuits suffer from one or more of following weaknesses:

- need for passive element matching [4], [11], [13]

- lack of electronic tunability [5]-[14], [17]

- excessive use of the active and/or passive elements [3]-[11], [13], [14], [16], [17]

- use of floating capacitor, which is not convenient to further fabricate in IC [5], [11], [13]-[17]

- use more than one active element [3]-[10], [12], [15], [16] Modern electronically controllable active building blocks $(\mathrm{ABBs})$ provide the flexibility and enabling a variety of

Manuscript received September 17, 2013; revised November 20, 2013.

The authors are with Department of Engineering Education, Faculty of Industrial Education, King Mongkut's Institute of Technology Ladkrabang, Bangkok, Thailand (e-mail: kcamornc@kmitl.ac.th, kawinai@kmitl.ac.th). circuit designs in analog signal processing. These circuits can be easily controlled by microcomputer or microcontroller which has been considerable attention. Also some circuits which use active building block can avoid the use of the external resistors. This will reduce the cost and chip area. Biolek proposed the interesting active building block namely, current differencing transconductance amplifier (CDTA) [18]. The modification of CDTA is later introduced namely, current controlled current differencing transconductance amplifier (CCCDTA) [19], which parasitic resistances at input port can be electronically controlled.

The aim of this paper is to propose a grounded inductance simulator, emphasizing on use of the CCCDTA. The features of proposed circuit are that: the proposed circuit consumes a few number of CCCDTA: it employs only single grounded capacitor, which is convenient to realize in IC: it does not need any matching condition of the element. In addition, the inductance can be controlled via input bias current. The performances of proposed circuit is illustrated by PSpice simulations, they show good agreement as depicted. Some applications as resonant circuits are given here to display the usefulness of the presented circuits.

\section{Proposed Inductance Simulator}

The main active element used to design the proposed inductance simulator is CCCDTA. Thus, the review of it will be shown here. The principle of CCCDTA was introduced in [19]. Its symbol and equivalent circuit are shown respectively in Fig. 1 a) and Fig. 1 b). The $\mathrm{p}$ and $\mathrm{n}$ which have finite resistances $\left(R_{p}\right.$ and $\left.R_{n}\right)$ are the current input terminals. $z, z_{c}$ (z-copy) and $\mathrm{x}$ are the output terminals. The difference of input currents $\left(i_{p}-i_{n}\right)$ will send to $\mathrm{z}$ terminal. The current at $z$ terminal is copied to $z_{c}$ terminal. The voltage at $z$ terminal is converted to the $x$-terminal current via a transconductance $g_{m}$. The characteristics of CCCDTA can be described by:

$$
\left[\begin{array}{l}
V_{p} \\
V_{n} \\
I_{z, z_{c}} \\
I_{x}
\end{array}\right]=\left[\begin{array}{cccc}
R_{p} & 0 & 0 & 0 \\
0 & R_{n} & 0 & 0 \\
1 & -1 & 0 & 0 \\
0 & 0 & 0 & \pm g_{m}
\end{array}\right]\left[\begin{array}{l}
I_{p} \\
I_{n} \\
V_{x} \\
V_{z}
\end{array}\right]
$$

If the CCCDTA is realized using BJT technology, $R_{p}, R_{n}$ and gm can be written as

$$
R_{p}=R_{n}=\frac{V_{T}}{2 I_{B 1}}
$$




$$
g_{m}=\frac{I_{B 2}}{2 V_{T}}
$$

Here $V_{T}$ is the thermal voltage. $I_{B 1}$ and $I_{B 2}$ are the bias currents used to control the intrinsic resistances and transconductance, respectively. The internal construction of BJT CCCDTA is shown in Fig. 2.

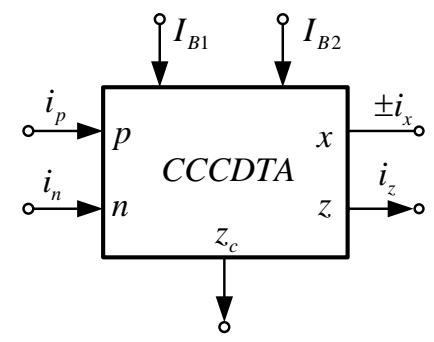

a)

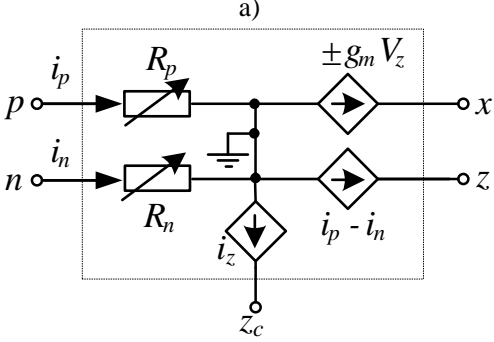

b)

Fig. 1 a) Electrical circuit symbol and b) Equivalent circuit of CCCDTA.

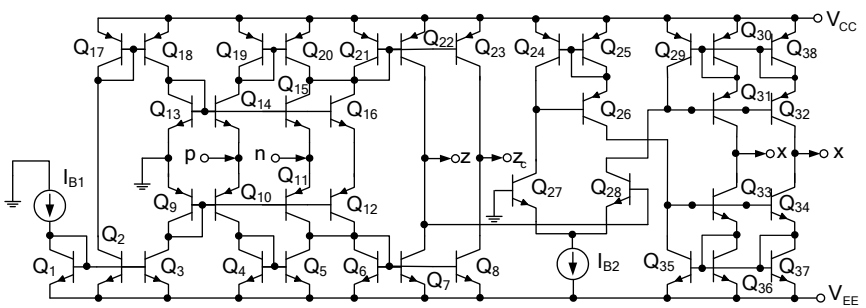

Fig. 2. Internal construction of BJT CCCDTA.

The proposed floating grounded simulator using CCCDTA is shown in Fig. 3. It is found in Fig. 3 that the proposed circuit uses only grounded capacitor and single active element without external resistor. This make the circuit is ideal for integration. The simulated impedance is given as

$$
Z_{\text {in }}=\frac{V_{\text {in }}}{I_{\text {in }}}=\frac{s C R_{p}}{g_{m}}
$$

From (4), it is obvious that the circuit shown in Fig. 3 performs a grounded inductor with a value

$$
L_{e q}=\frac{C R_{f}}{g_{m}}
$$

If $R_{p}$ and $g_{m}$ are equal to Eqs. (2) and (3), the inductance value is subsequently modified to

$$
L_{e q}=\frac{C V_{T}^{2}}{I_{B 1} I_{B 2}}
$$

It is clearly seen from (6) that, the inductance value $\mathrm{L}_{\mathrm{eq}}$ can be adjusted electronically by either $I_{B 1}$ or $I_{B 2}$.

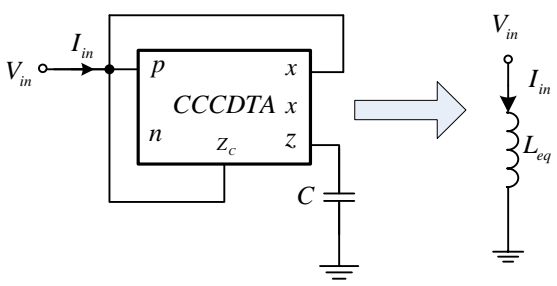

Fig. 3. Proposed inductance simulator.

\section{Simulation Results}

The performances of proposed inductance simulator are verified using PSpice. The CCCDTA is realized as showed in Fig. 2. The PNP and NPN transistors employed in the proposed circuit were simulated by respectively using the parameters of the PR200N and NR200N bipolar transistors of ALA400 transistor array from AT\&T [20]. The DC power supply voltages are $\pm 2.5 \mathrm{~V}$. The filter was designed with the following parameters of its components: $C=1 \mathrm{nF}, I_{B 1}=50 \mu \mathrm{A}$, and $I_{B 2}=200 \mu \mathrm{A}$.

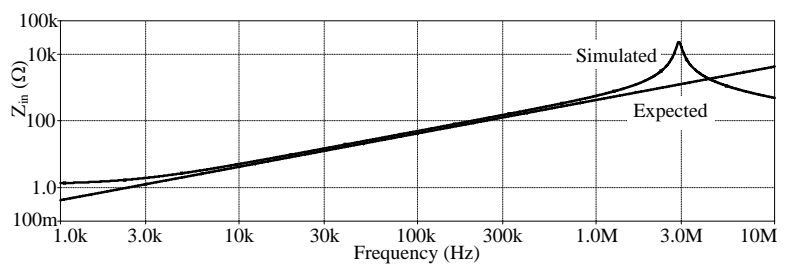

Fig. 4. Input impedance of the proposed inductance simulator.

To illustrate frequency responses of the inductance simulator, Fig. 4 shows the magnitude of input impedance. It should be noted that the usable frequency range of the proposed circuit is about $10 \mathrm{kHz}-2 \mathrm{MHz}$. At low and high frequencies, the internal parasitic elements covering capacitances and resistance degrade the performances of the proposed inductor. The calculated inductance value form (6) is $67.6 \mu \mathrm{H}$. While the simulated inductance value at usable frequency range is $79.14 \mu \mathrm{H}$. The phase response of the proposed inductance simulator is shown in Fig. 5. Fig. 6 shows impedance values with different $I_{B 1}$. It is confirmed that the simulated inductor can be adjusted by input bias current as shown in (6).

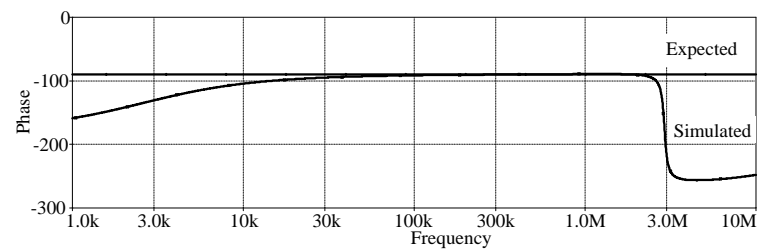

Fig. 5. Phase response.

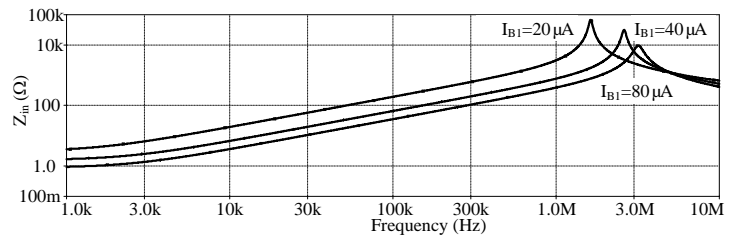

Fig. 6. Input impedance of the proposed inductance simulator for different $I_{B 1}$.

In order to show the domain performance of the proposed circuit, the second-order current-mode low-pass filter in Fig. 7 was performed. This filter is based on parallel RLC which 
has current as input. To achieve high output impedance, the dual output of $\mathrm{x}$ terminal of CCCDTA is required as shown in Fig. 8. The current $I_{L P}$ flows through grounded inductance with the following current transfer function:

$$
\frac{I_{L P}}{I_{\text {in }}}=\frac{\frac{1}{L C}}{s^{2}+s \frac{1}{R C}+\frac{1}{L C}}
$$

From Eq. (7), the pole frequency and quality factor are

$$
\omega_{0}=\sqrt{\frac{1}{L C}}
$$

and

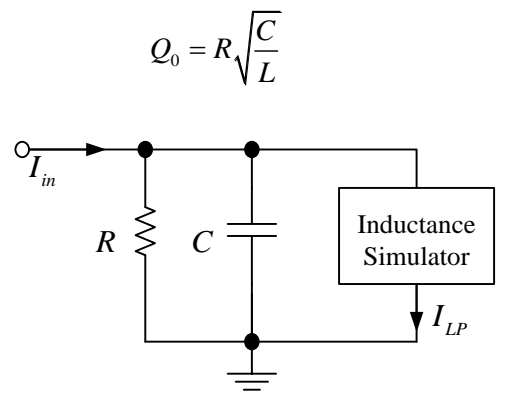

Fig. 7. Second order lowpass filter based on paralleled RLC.

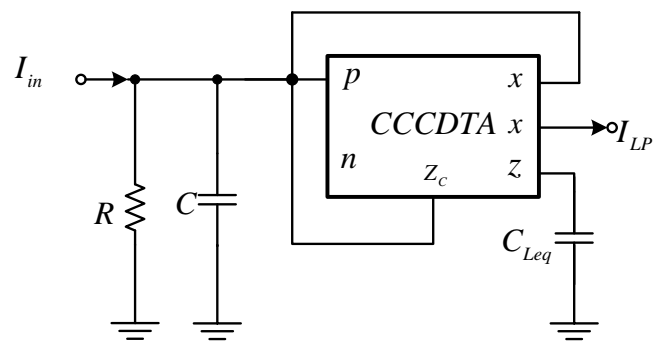

Fig. 8. Proposed current-mode LP filter.

The filter in Fig. 8 was verified with $I_{B 1}=50 \mu \mathrm{A}, I_{B 2}=200 \mu \mathrm{A}$, $C_{\text {Leq }}=1 \mathrm{nF}, R=1 \mathrm{k} \Omega$ and $C=1 \mathrm{nF}$. The gain response of the filter in Fig. 8 and ideal response is shown in Fig. 9. The value of ideal inductance is $67.6 \mu \mathrm{H}$. The low-pass responses with different $I_{B 1}$ are shown in Fig. 10. It is confirmed that the cut-off frequency can be adjusted by equivalent inductance by means of input bias current as shown in (6).

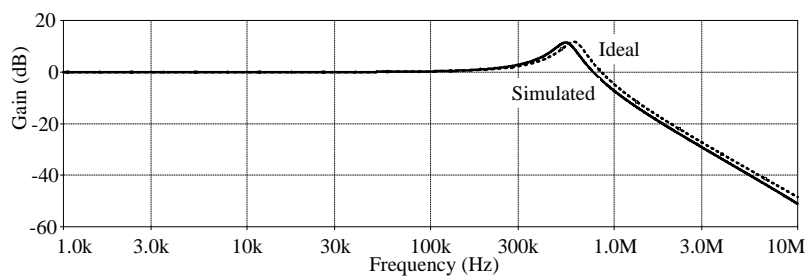

Fig. 9. Gain responses of the filter.

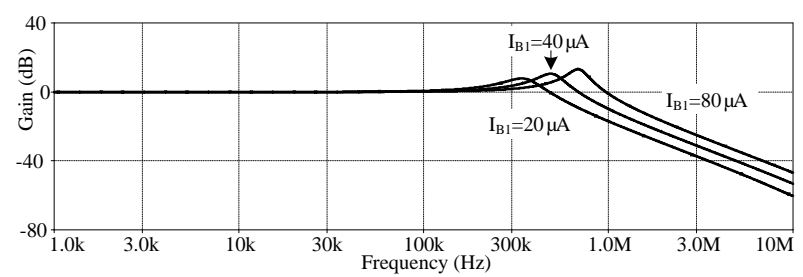

Fig. 10. Simulated gain of the filter in Fig. 8 with different $I_{B 1}$.

\section{CONCLUSION}

A circuit which can simulate grounded inductance simulator employing CCCDTA has been proposed. The presented circuit requires no critical component matching constraints and employs only single active element and grounded capacitor so it is easy to fabricate the proposed circuit in a fully integrated circuit technology. Due to electronic tunability, the proposed circuit is easily modified to use in control systems using a microcontroller. The simulation results agree well with the theoretical calculations.

\section{REFERENCES}

[1] A. Thanachayanont and A. Payne, "CMOS floating active inductor and its application to bandpass filter and oscillator designs," in Proc. IEE Circuits Device Syst., vol. 147, pp. 42-48, 2000.

[2] G. Haobijam, K. Manikumar, and R. Paily, "RFID circuit design with optimized CMOS inductor for monitoring biomedical signals," in Proc. 15th International Conference on Advanced Computing and Communications, pp. 203-208, 2007

[3] M. Higashimura and Y. Fukui, "Simulation of lossless floating inductance using two current conveyors and an operational transconductance amplifier," International Journal of Electronics, vol. 66, pp. 633-638, 1989.

[4] C. Koomgaew, W. Petchmaneelumka, and V. Riewruja, "OTA-based floating inductance simulator," ICROS-SICE International Joint Conference, pp. 857-860, 2009.

[5] J. S. Pena-Finol and J. A. Connelly, "Novel lossless floating immittance simulator employing only two FTFNs," Analog ICs and Signal Processing, vol. 29, pp. 233-235, 2001.

[6] G. Ferri, N. C. Guerrini, and M. Diqual, "CCII-based floating inductance simulator with compensated series resistance," Electronics Letters, vol. 39, no. 22, pp. 97-98, 2003.

[7] P. V. A. Mohan, "Grounded capacitor based grounded and floating inductance simulation using current conveyors," Electronics Letters, vol. 34, no. 11, pp. 1037-1038, 1998.

[8] K. Pal, "New inductance and capacitor floatation schemes using current conveyors," Electronics Letters, vol. 17, pp. 807-808, 1981.

[9] V. Singh, “Active RC single-resistance-controlled lossless floating inductance simulation using single grounded capacitor," Electronics Letters, vol. 17, pp. 920-921, 1981.

[10] W. Kiranon and P. Pawarangkoon, "Floating inductance simulation based on current conveyors," Electronics Letters, vol. 33, pp. 1748-1749, 1997.

[11] H. Kuntmana, M. Gulsoyb, and O. Cicekoglub, "Actively simulated grounded lossy inductors using third generation current conveyors," Microelectronics Journal, pp.245-250, 2000.

[12] K. Pal, "Floating inductance and FDNR using positive polarity current conveyors," Active and Passive Electronic Components, vol. 27, pp. 81-83, 2004

[13] E. Yuce, S. Minaei, and O. Cicekoglu, "A novel grounded inductor realization using a minimum number of active and passive components," ETRI Journal, vol. 27, pp. 427-432, 2005.

[14] U. Çam, F. Kaçar, O. Cicekoglu, H. Kuntman, and A. Kuntman, "Novel grounded parallel immittance simulator topologies employing single OTRA," AEU- International Journal Electronics and Communications, vol. 57, no. 4, pp. 287-290, 2003.

[15] M. Minaei, E. Yuce, and O. Cicekoglu, "Lossless active floating inductance simulator," in Proc. DELTA'06, KL, Malaysia, pp. 332-335, 2006.

[16] I. A. Khan and M. H. Zaidi, "A novel ideal floating inductor using translinear conveyors," Active and Passive Electronic Components, vol. 26, no. 2, pp. 87-89, 2003.

[17] M. Gulsoy and O. Çcekolu, "Lossless and lossy synthetic inductors employing single current differencing buffered amplifier," IEICE Transaction on Communications, vol. E88-B, no. 5, pp. 2152-2155, 2005.

[18] D. Biolek, "CDTA - Building block for current-mode analog signal processing," in Proc. the European Conference on Circuit Theory and Design 2003 - ECCTD'03, Krakow, Poland, pp. 397-400, 2003.

[19] M. Siripruchyanun and W. Jaikla, "CMOS current-controlled current differencing transconductance amplifier and applications to analog signal processing," International Journal of Electronics and Communications (AEU), vol. 62, pp. 277-287, 2008. 
[20] D. R. Frey, "Log-domain filtering: an approach to current-mode filtering," IEE Proc.-G, Circuits Syst. Devices, vol. 140, pp. 406-416, 1993.

A. Chaichana received the B. S. I. Ed. degree in electronics and computer and the M. Tech. Ed. electrical communications engineering from King Mongkut's Institute of Technology Ladkrabang (KMITL), Thailand in 1997 and 2002, respectively. He has been with Department of Engineering Education, Faculty of Industrial Education, King Mongkut's Institute of Technology Ladkrabang, Bangkok, Thailand since 1998. His research interests include electronic communications, analog signal processing and analog integrated circuit.
W. Jaikla received the B. S. I. Ed. degree in telecommunication engineering from King Mongkut's Institute of Technology Ladkrabang (KMITL), Thailand in 2002, M. Tech. Ed. in electrical technology and Ph.D. in electrical education from King Mongkut's University of Technology North Bangkok (KMUTNB) in 2004 and 2010, respectively. From 2004 to 2011 he was with Electric and Electronic Program, Faculty of Industrial Technology, Suan Sunandha Rajabhat University, Bangkok, Thailand. He has been with Department of Engineering Education, Faculty of Industrial Education, King Mongkut's Institute of Technology Ladkrabang, Bangkok, Thailand since 2012. His research interests include electronic communications, analog signal processing and analog integrated circuit. He is a member of ECTI, Thailand. 